\title{
STUDY OF 50 CASES OF OTOSCLEROSIS BY STAPEDOTOMY: OUR EXPERIENCE
}

\author{
P. B. Kameswar Rao' ${ }^{1}$ S. Ramesh², S. Devi Prasad ${ }^{3}$
}

${ }^{1}$ Associate Professor, Department of ENT, GEMS, Ragolu, Srikakulam, Andhra Pradesh

${ }^{2}$ Assistant Professor, Department of ENT, RIMS, Srikakulam, Andhra Pradesh.

${ }^{3}$ Consultant, Department of ENT, Sindhura Hospitals, Srikakulam, Andhra Pradesh.

\section{ABSTRACT}

\section{BACKGROUND}

Otosclerosis which is one of the commonest causes of non-suppurative conductive hearing loss. Small fenestra or stapedotomy is developed by Shea 1962 in which fenestration is made in foot plate of stapes and proper-sized Teflon piston is inserted between the long process of incus and fenestra. This procedure is less traumatic and therefore there are less chances of sensorineural loss.

\section{AIMS}

This study is aimed at assessing the longterm results in the light of observations made during the operation and the possible complications of stapedotomy, results and follow-up.

\section{METHODS AND MATERIAL}

The present study was conducted on 50 ears of otosclerosis who were subjected to stapedotomy, (stapedotomy with soft tissue seal with vein graft, ear lobule fat or perichondrium). The selection was made from the patients attending ENT OPD of GEMS Hospital, Ragolu, Srikakulam.

\section{RESULTS AND CONCLUSIONS}

The disease is mainly observed in $2^{\text {nd }} \& 3^{\text {rd }}$ decades. Out of the 50 cases studied, 33 cases are in this age group. $74 \%$ of the patients showed closure of a-b Gap to within $10 \mathrm{~dB} .18 \%$ of the patients showed closure of a-b gap 11-20 dB. The disturbance of taste i.e., metallic taste was complained in 5 patients of the study, it was sectioned in 3 cases and stretched in 2 cases, complete recovery was noticed in 4-5 months, vertigo in 9 cases and SNHL in one case.

\section{KEYWORDS}

Otosclerosis, Stapedotomy, A-B Gap, Sensorineural Loss, Vertigo.

HOW TO CITE THIS ARTICLE: Rao PBK, Ramesh S, Prasad SD. Study of 50 cases of otosclerosis by stapedotomy- our experience. J. Evolution Med. Dent. Sci. 2016;5(38):2295-2298, DOI: 10.14260/jemds/2016/533

\section{INTRODUCTION}

Otosclerosis which is one of the commonest causes of nonsuppurative conductive hearing loss. Valsalva was the first to describe otosclerosis in 1735 as ankylosis of the stapes to the margins of the oval window. ${ }^{1}$ The technique of surgery for otosclerosis has evolved in the hands of different surgeons and there is diversity of opinion among the otologists about the type of operations that will give satisfactory and lasting results. In this effort, new modifications have been introduced from time to time.

Stapedectomy is an operation in which the stapes suprastructure and footplate are removed and replaced by prosthesis. It was first performed by Dr. John J. Shea. ${ }^{2}$ Small fenestra or stapedotomy is developed by Shea 1962 in which fenestration is made in footplate of stapes and proper-sized Teflon piston is inserted between the long process of incus and fenestra. This procedure is less traumatic and therefore there are less chances of sensory neural loss.

The principle of stapedotomy is to form a calibrated hole in the foot plate. There are four basic variations of stapedotomy.

Financial or Other, Competing Interest: None.

Submission 21-03-2016, Peer Review 16-04-2016,

Acceptance 21-04-2016, Published 11-05-2016.

Corresponding Author:

Dr. S. Ramesh,

Assistant Professor

RIMS,

Srikakulam-532001,

Andhra Pradesh.

E-mail: rameshseepana@rediffmail.com

DOI: $10.14260 /$ jemds/2016/533
1. Drilling with a micro drill (Portman \& Claverie).

2. Micro hook technique by Marquet with removal of small pieces of footplate to enlarge stapedotomy hole.

3. Hand - Drill of various sizes to perform fenestra (Fisch)

4. Stapes tendon preservation or re-construction (Marquet Colletti causes), maintaining the stapedial reflex.

Both stapedectomy and stapedotomy give excellent results for surgical treatment of otosclerosis. In experienced hands, both techniques give satisfactory and stable longterm results. ${ }^{3}$ The success rate of both stapedectomy and stapedotomy greatly depends on the surgical skills of the surgeon and accurate determination of the prosthesis length. 4,5 The study of Thamjarayakul et al. "Stapes fixation surgery: Stapedectomy versus stapedotomy" who came to the conclusion that stapedotomy is less prone to complications than stapedectomy. ${ }^{6}$

\section{NEW DEVELOPMENTS}

\section{Stapedotomy with Stapedial Tendon Preservation}

In which stapedial tendon is not cut and the stapedial suprastructure with the preserved muscle tendon was transpositioned on to the longer arm of the incus and secured with a wire loop. Preserving the stapedius tendon can be done with laser. Patients having this tendon functioning have less intolerance to noise, hear better in noise, and have less chance of damage to the inner ear from pressure changes.

\section{Laser Stapedotomy}

The Laser stapedectomy is a procedure which permits the surgeon to operate without touching the stapes. An opening is made in the frozen stapes footplate and prosthesis is inserted 
to allow sound waves to enter the inner ear which restore the sound conducting mechanism and hearing. There is very little bleeding or scarring in this procedure and patient can go home several hours after surgery.

\section{Laser STAMP (Laser Stapedotomy Minus Prosthesis)}

In 1995, Dr. Silverstein developed a new technique called Laser STAMP. The laser is used to free the frozen stapes bone in patients with minimal otosclerosis, preserving most of the patient's normal stapes bone. This restores the patient's hearing without using a prosthesis. The advantages of preserving most of the patient stapes include reduced sensitivity to noise, decreased incidence of noise damage to the ear and reduced chances of trauma to the inner ear from changes in pressure flying or diving.

\section{Endoscopic Stapedotomy}

Endoscope-assisted stapedotomy was first described by Poe in $2000 .{ }^{7}$ there is only one publication fully on endoscopic stapedotomy (ES). ${ }^{8}$

\section{AIM OF THE STUDY}

This study is aimed at assessing the longterm results in the light of observations made during the operation and the possible complications of stapedotomy, results and follow-up.

\section{MATERIALS AND METHODS}

The present study was conducted on 50 ears of otosclerosis, who were subjected to stapedotomy, (stapedotomy with soft tissue seal with vein graft, ear lobule fat or perichondrium). The selection was made from the patients attending ENT OPD of GEMS Hospital, Ragolu, Srikakulam.

After thorough interrogation and detailed clinical examination, the relevant data was recorded on a special proforma.

\section{Criteria of Selection of Cases}

1. Progressive deafness of conductive type with onset in early adult life, accompanied by tinnitus and sometimes paracusis.

2. Normal or near-normal appearance of the tympanic membranes.

3. Normal mobility of the membrane.

4. No other apparent cause of deafness.

5. Characteristic changes in the audiogram.

a. Sufficient air-bone gap.

6. Characteristic features in impedance.

a. As or A type tympanogram.

b. Absent acoustic reflex of 'on-off' effect.

\section{Exclusion Criteria to Surgery}

1. A medically unfit patient.

2. Active otitis media.

3. Perforated tympanic membrane.

4. An only hearing ear that does well with amplification.

5. Presence of vertigo and clinical evidence of labyrinthine hydrops.

6. Pregnancy.

7. Presence of inner ear malformation.

Post-operatively, all the patient are instructed to avoid swimming and exposure to noise. All are advised to report for review after 1 month and then every 3 months. Post-operative audiometry was done after 1 month \& 3 months.

\section{Criteria of Success}

The success of operation was determined by the degree of closure of air-bone gap in speech frequencies $(500,1000$ \& $2000 \mathrm{~Hz}$ ) and the results were classified into four categories. ${ }^{6}$

Remaining air-bone gap $10 \mathrm{~dB}$ or less

Remaining air-bone gap $11-20 \mathrm{~dB}$ - Excellent

Air-bone gap persisting at pre-operative

Level or insignificant rise - Good

Deterioration of hearing

- Poor

- Worse

\section{OBSERVATIONS}

The present series consists of a study of 50 otosclerotic ears which were subjected to stapedotomy. The observation and inferences drawn as a result of the study are discussed below.

\section{Age}

The disease is mainly observed in $2^{\text {nd }} \& 3^{\text {rd }}$ decades. Out of the 50 cases studied, 33 cases are in this age group.

\begin{tabular}{|c|c|}
\hline Age Group & No. of Patients \\
\hline $11-20$ & 4 \\
\hline $21-30$ & 16 \\
\hline $31-40$ & 17 \\
\hline $41-50$ & 13 \\
\hline $51 \&$ Above & 0 \\
\hline & \\
\hline
\end{tabular}

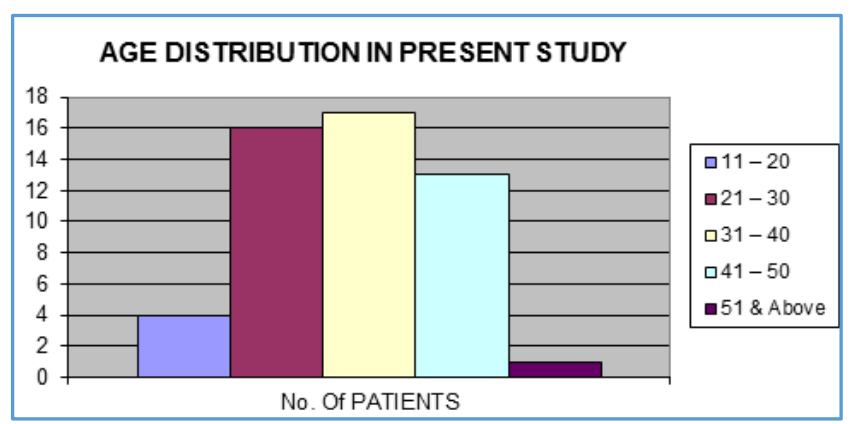

\section{Sex Distribution}

Females were found to be slightly dominating over males. Of the 50 cases studied, 26 were females and 24 were males.

\begin{tabular}{|c|c|}
\hline Male & 24 \\
\hline Female & 26 \\
\hline Total Cases & $\mathbf{5 0}$ \\
\hline \multicolumn{2}{|c|}{ Table 2 } \\
\hline \multicolumn{2}{|c|}{}
\end{tabular}

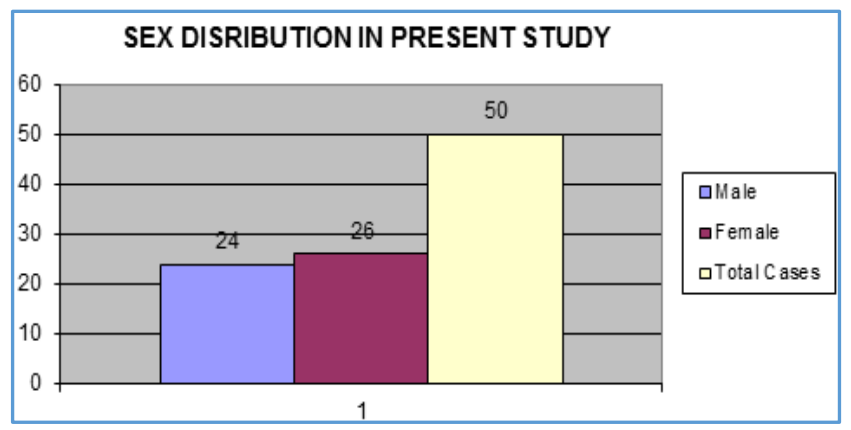


Side of Ear Affected

\begin{tabular}{|c|c|}
\hline Both sides & 47 \\
\hline Right side & 1 \\
\hline Left side & 2 \\
\hline \multicolumn{2}{|c|}{ Table 3 } \\
\hline
\end{tabular}

$94 \%$ patients presented with bilateral symptoms and $6 \%$ had unilateral symptoms.

\section{Preoperative Pure Tone Average}

\begin{tabular}{|c|c|}
\hline Mild (16-40) & Nil \\
\hline Moderate (41-55) & 15 \\
\hline Moderately severe (56-70) & 35 \\
\hline Table 4 \\
\hline
\end{tabular}

$30 \%$ of the patients presented with moderate hearing loss and $70 \%$ of the patients presented with moderately severe hearing loss. There are no patients with minimal or profound hearing loss.

\section{Preoperative Air-Bone Gap}

\begin{tabular}{|c|c|}
\hline A B GAP & \\
\hline $25-35$ & 22 \\
\hline $36-45$ & 28 \\
\hline \multicolumn{2}{|c|}{ Table 5 } \\
\hline
\end{tabular}

$44 \%$ of the patients showed air-bone gap between 25 $350 \mathrm{~dB}$ and $66 \%$ of the patients showed air -bone gap between 36- $45 \mathrm{~dB}$.

Tympanogram

\begin{tabular}{|c|c|}
\hline TYPE & 27 \\
\hline As & 23 \\
\hline A & \\
\hline \multicolumn{2}{|c|}{ Table 6 } \\
\hline
\end{tabular}

The study showed as type of curve in $54 \%$ of the patients and a type of curve in $46 \%$ of the patients.

Length of Piston used in the Present Study

\begin{tabular}{|c|c|}
\hline Length (mm) & Number \\
\hline 3.75 & 3 \\
\hline 4 & 11 \\
\hline 4.25 & 31 \\
\hline 4.5 & 5 \\
\hline \multicolumn{2}{|c|}{ Table 7 } \\
\hline
\end{tabular}

Most commonly used piston in our study is $4.25 \mathrm{~mm}$ length with diameter of $0.4 \mathrm{~mm}$ with good results.

Post-Operative Air-Bone Gap

\begin{tabular}{|c|c|}
\hline Post op AB GAP & Number \\
\hline$<10$ & 37 \\
\hline $11-20$ & 9 \\
\hline$>21 \quad$ Table 8 \\
\hline \multicolumn{2}{|c|}{} \\
\hline
\end{tabular}

$74 \%$ of the patients showed closure of a-b Gap to within $10 \mathrm{~dB} .18 \%$ of the patients showed closure of a-b gap 11-20 dB.

Complications following Small Fenestra Stapedectomy

\begin{tabular}{|c|c|}
\hline Complications & Number \\
\hline Vertigo & 9 \\
\hline SNHL & 1 \\
\hline Injury to chorda tympani & 5 \\
\hline Tympanic membrane tear & 1 \\
\hline \multicolumn{2}{|c|}{ Table 9 } \\
\hline
\end{tabular}

\section{DISCUSSION}

The present series consists of a study of 50 otosclerotic ears which were subjected to stapedotomy, their demographic information, clinical result, audiological evaluation are recorded and analysed. Anatomical abnormalities seen during the surgery, complications following small fenestra stapedectomy are also analysed. The disease is mainly observed in $2^{\text {nd }} \& 3^{\text {rd }}$ decades. Out of the 50 cases studied, 33 cases are in this age group.

Females were found to be slightly dominating over males. Of the 50 cases studied, 26 were females and 24 were males. $94 \%$ patients presented with bilateral symptoms and $6 \%$ had unilateral symptoms. Comparison of studies for bilateral involvement with the other studies; in Glasscock study $72 \%$, Ginsberg et al 80\%; and in Levy et al study it was $66 \% .30 \%$ of the patients presented with moderate hearing loss and $70 \%$ of the patients presented with moderately severe hearing loss. There are no patients with minimal or profound hearing loss. $44 \%$ of the patients showed air-bone gap between $25-35 \mathrm{~dB}$ and $66 \%$ of the patients showed airbone gap between $36-45 \mathrm{~dB}$. The study showed as type of curve in $54 \%$ of the patients and A type of curve in $46 \%$ of the patients.

\section{PROBLEMS FACED DURING SURGERY} Injury to Chorda Tympani Nerve

When the posterior part of the bony annulus is removed to visualise the stapes, the chorda tympani nerve (CTN) can be occasionally touched and stretched. ${ }^{9}$ The reported rate of postoperative taste disorders or tongue symptoms after stapes surgery is $20-60 \%$ in patients whose CTN was manipulated or transected.

The disturbance of taste i.e., metallic taste was complained in 5 patients of the study, it was sectioned in 3 cases and stretched in 2 cases, complete recovery was noticed in 4-5 months.

\section{Abnormalities of Facial Canal}

The facial canal is in a very vulnerable position during the extraction of the stapedial foot plate and any abnormalities in the course of the nerve or dehiscence of the canal render it more so. In our study, we encountered 6 cases of dehiscence of facial canal and 6 cases of overhanging facial nerve.

\section{Prosthesis}

Various types of prosthesis have been used to rebuild the conductive mechanism. Teflon piston was well tolerated in animal tissues. The prosthesis length is measured from the under surface of the long process of the incus to the footplate plus $0.25 \mathrm{~mm}$ in our study. Most commonly used piston in our study is $4.25 \mathrm{~mm}$ length with diameter of $0.4 \mathrm{~mm}$ with good results.

\section{Complications following Small Fenestra Stapedectomy}

Most of complications associated with stapedotomy typically result from either cochlear or labyrinthine trauma. As manifested by elevated pure tone thresholds and reduced speech discrimination scores, cochlear trauma leads to sensorineural hearing loss in less than $2 \%$ of patients. Labyrinthine damage causing vertigo occurs in approximately $2 \%$ of patients. 


\section{Vertigo}

Vestibular reactions are due to irritation of the labyrinth and appear in the form of nausea, vomiting, unsteadiness of gait and nystagmus. They are usually mild and last for 2-3 days. In the present study, 5 patients had such disturbance and subsided within 2 to 3 days, 3 cases subsided within one week and one case subsided in 4 weeks. Infection is hardly seen after stapes operation performed under careful aseptic technique.

\section{Sensorineural Hearing Loss [SNHL]}

The most devastating complication of stapes surgery is sensorineural hearing loss which occurs in less than $2 \%$ of cases. Sensorineural hearing loss may be mild or isolated to high frequencies. When sensorineural hearing loss is suspected, prednisone is started immediately and tapered. In our study, one case had SNHL.

\section{CONCLUSIONS}

The present study was undertaken to assess the results of stapedotomy in cases of otosclerotic ears and analysed the results in the light of observation made at the time of operation and in postoperative period.

\section{The following Conclusions were drawn from the Study: Clinical Data}

The disease is mainly observed in $2^{\text {nd }} \& 3^{\text {rd }}$ decades. Out of the 50 cases studied, 33 cases are in this age group.

Females were found to be slightly dominating over males. Of the 50 cases studied, 26 were females and 24 were males.

$94 \%$ patients presented with bilateral symptoms and $6 \%$ had unilateral symptoms.

The study showed as type of curve in $54 \%$ of the patients and A type of curve in $46 \%$ of the patients.

\section{Observations at Operations}

a. Sectioning or stretching of chorda tympani nerve caused transient disturbance of taste which recovered in 3-4 months.

b. Anatomical abnormalities like dehiscent facial canal will not cause any difficulty in dealing and proceeding with the surgery.

c. Most commonly used piston in our study is $4.25 \mathrm{~mm}$ length with diameter of $0.4 \mathrm{~mm}$ with good results.

\section{Postoperative Course}

It was marked by mild labyrinthine disturbances like nausea, vomiting and vertigo in 9 cases, which are subsided in a week. In our study, one case had SNHL.

\section{Follow-up}

- Large majority of the patients maintained the improvement in hearing pattern gained initially till the period of follow-up.

- $74 \%$ of the patients showed closure of $a-b$ Gap to within $10 \mathrm{~dB} .18 \%$ of the patients showed closure of $a-b$ gap 11$20 \mathrm{~dB}$.

In 3 cases, there is only slight improvement.

\section{REFERENCES}

1. Makarem AO, Hoang TA, Lo WW, et al. Cavitating otosclerosis: clinical, radiologic, and histopathologic correlations. Otol Neurotol 2010;31(3):381-384.

2. Shea JJ. Fenestration of the oval window. Ann Otol Rhinol Laryngol 1958;67(4):932-51.

3. House HP, Hansen MR, Al Dakhail AA, et al. Stapedectomy versus stapedotomy: comparison of results with longterm follow-up. Laryngoscope 2002;112(11):20462050.

4. Paum BK, Pollak AM, Fisch U. Utricle, saccule and cochlear duct in relation to stapedotomy: a histologic temporal bone study. Ann Oto Rhinol Laryngol 1991;100(12)966-970.

5. Fisch U. Stapedotomy versus stapedectomy. Otol Neurotol 2009;30(8):1166-1167.

6. Thamjarayakul T, Supiyaphun P, Snidvongs K. Stapes fixation surgery: stapedectomy versus stapedotomy. Asian Biomedicine 2010;4(3):429-434.

7. Poe DS. Laser-assisted endoscopic stapedectomy: a prospective study. Laryngoscope 2000;110 (5 Pt 2 Suppl 95):1-37.

8. Nogueira Ju'nior JF, Martins MJ, Aguiar CV, et al. Fully endoscopic stapes surgery (stapedotomy): technique and preliminary results. Braz J Otorhinolaryngol 2011;77(6):721-727.

9. Miuchi S, Sakagami M, Tsuzuki K, et al. Taste disturbance after stapes surgery-clinical and experimental study. Acta Otolaryngol Suppl 2009;562:71-78. 